\title{
Hubungan Panjang Berat dan Faktor Kondisi Relatif Lima Spesies Ikan di Sungai Suwi Muara Ancalong, Kutai Timur
}

\section{Length Weight Relationship and Relative Condition Factor Five Fish Species in Suwi River, Muara Ancalong, Kutai Timur}

\author{
Rudy Agung Nugroho ${ }^{1 *}$, Apri Pauci Florentino ${ }^{1}$, Lariman ${ }^{2}$, Retno Aryani $^{1}$, Rudianto ${ }^{1}$, \\ Monica Kusneti ${ }^{3}$ \\ ${ }^{1}$ Laboratorium Fisiologi, Perkembangan dan Molekuler Hewan, Jurusan Biologi, Fakultas Matematika dan \\ Ilmu Pengetahuan Alam, Universitas Mulawarman. \\ Jl. Barong Tongkok No 4 Gn Kelua, Samarinda, Kalimantan Timur, Indonesia \\ ${ }^{2}$ Laboratorium Ekologi dan Sistematika Hewan, Jurusan Biologi, Fakultas Matematika dan Ilmu \\ Pengetahuan Alam, Universitas Mulawarman. \\ Jl. Barong Tongkok No 4 Gn Kelua, Samarinda, Kalimantan Timur, Indonesia \\ ${ }^{3}$ Yayasan Khatulistiwa, Samarinda, Kalimantan Timur, Indonesia \\ Jl. Untung Suropati, Perum Karpotek Blok UU no 15, Samarinda, Kalimantan Timur, Indonesia \\ Email: rudyagung.nugroho@fmipa.unmul.ac.id *Penulis Korespondensi
}

\begin{abstract}
The length-weight relationship of fish and the relative condition factor provides an overview of the fish growth conditions in the river. The purpose of this study were to determine the length-weight relationship and condition factor of five fish species in the Suwi River wetlands. The method of catching fish used gill nets, ceiling nets, fishing rods, traps, and other nets. The research was conducted for two months in the Suwi river wetlands. The results showed that the length-weight relationship of five fish were varied, Ompok bimaculatus had b value 2.93, Helostoma temminckii (b value 2.15), Mystus nemurus (b value 2.62), and Channa micropeltes (b 2.61) which indicated a negative allometric growth pattern. Meanwhile, Leptobarbus hoevenii (b 3.12) was a positive allometric growth pattern. Relative weight (Wr) of Ompok bimaculatus 101.28 \pm 19.13, Helostoma temminckii 101.05 \pm 15.51 , Mystus nemurus 100.95 \pm 14.84 , Channa micropeltes $101.09 \pm 14.14$, Leptobarbus hoevenii 103.71 \pm 34.57. Condition factor above 100, indicates sufficient food availability or low predator density.
\end{abstract}

Keywords: Wetland, Fish, Condition Factor, Length-weight, Suwi River, Ancalong Estuary

\begin{abstract}
Abstrak
Hubungan panjang berat ikan dan faktor kondisi ikan di sungai Suwi memberikan gambaran tentang kondisi pertumbuhan ikan. Penelitian ini bertujuan untuk mengevaluasi hubungan panjang berat dan faktor kondisi spesies ikan di perairan lahan basah sungai Suwi. Metode penangkapan ikan menggunakan jaring insang, jaring langit-langit, alat pancing, perangkap, dan jala untuk mengetahui hubungan panjang berat dan faktor kondisi spesies ikan di perairan lahan basah sungai Suwi yang dilakukan selama 2 bulan. Hasi penelitian menunjukan panjang berat kelima jenis ikan bervariasi, ikan lais/lepok (Ompok bimaculatus) nilai b 2,93, biawan (Helostoma temminckii) nilai b 2,15, baung (Mystus nemurus) nilai b 2,62, dan toman (Channa micropeltes) nilai b 2,61. Nilai b menunjukan pola pertumbuhan allometrik negatif, sedangkan ikan jelawat (Leptobarbus hoevenii) nilai b 3,12 yaitu pola pertumbuhan allometrik positif. Nilai berat relatif (Wr) ikan lais/lepok (Ompok bimaculatus) 101,28 \pm 19,13, biawan (Helostoma temminckii) 101,05 \pm 15,51, baung (Mystus nemurus) 100,95 $\pm 14,84$, toman (Channa micropeltes) $101,09 \pm 14,14$, ikan jelawat (Leptobarbus hoevenii) $103,71 \pm 34,57$. Jika nilai $\mathrm{Wr}$ di atas 100, menunjukkan ketersediaan makanan cukup atau kepadatan predator rendah.
\end{abstract}

Kata Kunci: Lahan basah, Ikan, Kondisi, Panjang Berat, Sungai Suwi, Muara Ancalong 



\section{Pendahuluan}

Keanekaragaman ikan di Indonesia dikenal sangat tinggi, dapat dilihat dari luas kawasan konservasi pada tahun 2017 mencapai 19,14 juta Ha dan angka potensi sumber daya ikan pada tahun 2017 di Indonesia mencapai 12,54 juta ton/tahun (Perikanan, 2018). Keanekaragaman ikan di Indonesia sangat beragam, Setidaknya keragaman ada kurang lebih 8500 jenis ikan, 800 jenis ikan diantaranya berada di habitatnya yaitu sungai, danau ataupun rawa-rawa (Trijoko \& Panoto, 2006).

Ikan dapat ditemukan dalam jumlah yang besar di suatu perairan jika kondisi lingkungan perairan tersebut sesuai dengan kebutuhan hidupnya dan memiliki ketersediaan makanan yang memadai. Secara umum, ikan mengalami pertumbuhan terus menerus sepanjang hidupnya. Pertumbuhan mempunyai hubungan perubahan dalam ukuran, jumlah, ataupun dimensi pada tataran sel, jaringan organ atau individu yang biasanya diukur dengan meliputi berat, panjang, umur tulang, serta keseimbangan metabolik (Muchlisin \& Cheng, 2014).

Salah satu perairan yang memiliki sumber daya ikan air tawar adalah perairan sungai Suwi yang terletak di Kecamatan Muara Ancalong, Kabupaten Kutai Timur. sungai Suwi mempunyai keanekaragaman jenis ikan yang cukup tinggi sehingga dapat dimanfaatkan untuk memenuhi kebutuhan hidup ekonomi para nelayan (Nugroho et al., 2016). Setidaknya pada tahun 2015, di sungai Suwi, Muara Ancalong ditemukan 11 famili dan 7 ordo ikan (Nugroho et al., 2016). Sementara itu, penelitian sebelumnya mengenai telaah hubungan panjang-berat ikan telah beberapa dilakukan, diantaranya pada jenis ikan layang (Decapterus ruselli) yang berasal dari perairan Teluk Likupang, Sulawesi Utara (Manik, 2009), ikan sebelah (Psettodes erumel) yang ada sekitar perairan Jepara (Redjeki, 2003), serta jenis-jenis ikan asli yang berasal dari Danau Sentani, Papua (Umar \& Lismining, 2006).

Ikan nila dan ikan belanak tertangkap di sungai Mantang Guru. Kec Madat, Kab Aceh Timur (Muttaqin \& Aliza, 2016), lalu ikan kapas-kapas tertangkap dengan alat tangkap Sero di perairan Tondonggeu, Kec Abeli, Kota
Kendari (Ermayana et al., 2018). Namun, penelitian mengenai hubungan panjang berat dan faktor kondisi ikan terutama ikan lais (Ompok bimaculatus), biawan (Helostoma temminickii), baung (Mystus nemurus), toman (Channa micropeltes) dan jelawat (Leptobarbus hoevenii) di sungai Suwi belum pernah dilakukan. Jenis-jenis ikan tersebut merupakan jenis ikan yang sering ditangkap oleh nelayan setempat dan dikonsumsi serta diperjualbelikan (Nugroho et al., 2016).

\section{Metode Penelitian}

\section{Waktu dan Tempat}

Penelitian ini dilakukan selama dua bulan, yaitu Juli dan Agustus 2018. Penelitian dilakukan di sepanjang perairan Sungai Suwi. Kecamatan Muara Ancalong, Kabupaten Kutai Timur, Kalimantan Timur. Pengambilan sampel dilakukan di empat lokasi pengambilan sampel di sepanjang Sungai Suwi (Gambar 1).

\section{Prosedur Pengambilan Sampel}

Prosedur sampling adalah purposive sampling didasarkan kriteria tertentu dari peneliti, yaitu ciri atau sifat-sifat populasi yang telah dideterminasi sebelumnya. Sampel ikan adalah 5 jenis ikan: Ompok bimaculatus (Lais/Lepok), Helostoma temminckii (Biawan), Mystus nemurus (Baung), Leptobarbus hoevenii (Jelawat), dan Channa micropeltes (Toman) dengan kriteria bobot dan ukuran panjang ikan yang tidak jauh berbeda, di sepanjang sungai Suwi. Jumlah ikan yang tertangkap tidak ada jumlah minimum, namun berdasarkan jumlah ikan yang tertangkap oleh nelayan pada saat penangkapan dan waktu penangkapan.

Pengambilan dilakukan selama 7 hari pada pengambilan pertama lalu dilanjutkan hal yang sama pada pengambilan sampel berikutnya sampai dengan tiga kali pengambilan sampel. Titik pengambilan sampel: hulu 2 titik tengah 2 titik, hilir 2 titik dan sungai suwi (Loa Bekara) dilakukan dengan 2 titik tempat pengambilan sampel. Pengambilan ikan dengan jaring insang (Gill net), jaring langit-langit, alat pancing, perangkap, dan jala dipasangkan selama 8 jam setelah itu diperiksa, diukur berat dan panjang, dan didokumentasikan (Muchlisin and Cheng, 2014). 


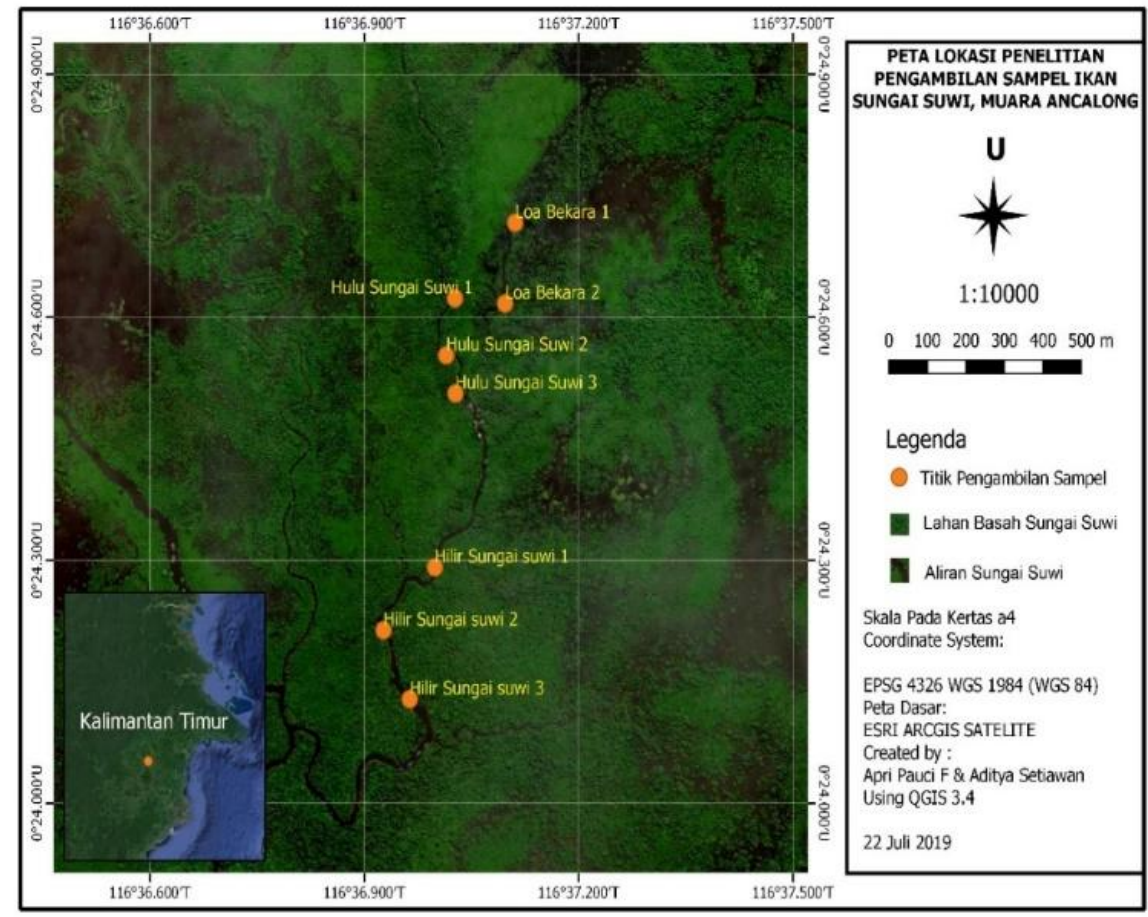

Gambar 1. Peta Sungai Suwi Muara Ancalong, Kabupaten Kutai Timur, Provinsi Kalimantan Timur

\section{Analisis data panjang - berat}

Hubungan panjang berat model allometric linear (LAM) yang berguna untuk perhitungan parameter a dan $b$. Perhitungan tersebut melalui pengukuran perubahan berat dan panjang. Sementara itu, koreksi bias yang ada diperubahan berat rata-rata dari unit logaritma digunakan sebagai perhitungan prediksi berat pada parameter panjang sesuai dengan persamaan allometric berikut:

$$
\mathrm{W}=\mathrm{a} \mathrm{Lb}
$$

$\mathrm{W}$ adalah berat ikan (g), $\mathrm{L}$ adalah panjang total ikan $(\mathrm{mm})$, a dan $\mathrm{b}$ adalah parameter (De-Robertis dan William, 2008).

\section{Faktor kondisi}

Berat relatif $(\mathrm{Wr})$ dan koefisien $(\mathrm{K})$ faktor kondisi digunakan untuk mengevaluasi faktor kondisi dari setiap individu. Berat relatif (Wr) ditentukan berdasarkan persamaan (Rypel dan Richter, 2008) sebagai berikut:

$$
\mathrm{Wr}=(\mathrm{W} / \mathrm{Ws}) \times 100
$$

$\mathrm{Wr}$ adalah berat relatif, $\mathrm{W}$ berat tiaptiap ikan, dan Ws adalah berat standar yang diprediksi dari sampel yang sama karena dihitung dari gabungan regresi panjang berat melalui jarak antar spesies:

$$
\mathrm{Ws}=\mathrm{a} \mathrm{Lb}
$$

Koefisien kondisi Fulton (K) ditentukan berdasarkan Okgerman (2005) dengan rumus sebagai berikut:

$$
\mathrm{K}=\mathrm{WL}-3 \times 100
$$

Dimana $\mathrm{K}$ adalah faktor kondisi Fulton, W adalah berat ikan (g), L adalah panjang ikan $(\mathrm{mm})$ dan -3 adalah koefisien panjang atau faktor koreksi, untuk memastikan bahwa nilai $\mathrm{K}$ cenderung bernilai 1 . Pada umumnya, nilai $\mathrm{b}$ mempunyai ketergantungan pada situasi fisiologis dan lingkungan. Sebagai contoh adalah suhu, $\mathrm{pH}$, salinitas, letak geografis dan teknik sampling (Jennings dan Reynolds, 2001). Faktor lain adalah kondisi biologis yaitu perkembangan gonad serta ada dan tidaknya makanan (Froese, 2006). Data parameter lingkungan yang terukur dalam rentang penelitian yaitu suhu $\pm 27,8{ }^{\circ} \mathrm{C}$; kedalaman sungai 70-80 cm; pH 5,5-6.5.

\section{Hasil dan Pembahasan}

Jumlah ikan yang tertangkap selama penelitian sebanyak 467 ekor, yang terdiri dari 111 lais/lepok (Ompokbimaculatus), 215 
biawan (Helostomatemminckii), 20 baung (Mystus nemurus), 30 toman (Channamicropeltes), dan 92 ikan jelawat (Leptobarbus hoevenii). Ikan yang tertangkap merupakan ikan dengan ukuran konsumsi dan dengan variasi ukuran berat dan panjang seperti disampaikan dalam Tabel 1.

Hasil penelitian juga menunjukan adanya nilai koefisien korelasi (r) berkisar 0,71 sampai 0,91 (Tabel 1). Nilai koefisien korelasi yang tinggi menunjukan hubungan yang erat antara berat dan pertumbuhan Panjang (Muchlisin et al., 2014). Hasil analisis hubungan panjang berat yang didapatkan yaitu nilai koefisien determinasi (R2) berkisar 0,509 sampai $0,831 \%$, nilai (R2) yang besarnya hampir mendekati satu, menunjukan bahwa keragaman yang dipengaruhi oleh faktor lain di lokasi tersebut kemungkinannya cukup kecil (Walpole, 1995).

Hasil perhitungan menunjukan berat yang diamati (observed weight) yaitu nilai $\mathrm{W}$ (gr) lebih tinggi daripada berat yang di prediksi (predicted weight) yaitu nilai $\mathrm{Wr}$, salah satu jenis ikan yang tertinggi ialah ikan toman (Channamicropeltes) dengan berat yang diperoleh 312,06 \pm 94,37 lebih tinggi dari berat yang diprediksi 308,14 $\pm 75,91$, ini mengindikasikan kondisi perairan yang baik mendukung pertumbuhan ikan. Besarnya faktor kondisi ikan dipengaruhi oleh beberapa faktor, antara lain kondisi organisme, dan jumlah organisme yang ada, ketersediaan makanan dan kondisi dari lingkungan perairan (Effendie, 1997).

Tabel 1. Hubungan Panjang Berat dan Faktor Kondisi (Rerata \pm SD) dari Kelima Jenis Ikan

\begin{tabular}{lccccc}
\hline \multicolumn{1}{c}{ Parameter } & Lais/Lepo & Biawan & Baung & Toman & Jelawat \\
\hline \hline Panjang Total (TL) & $153-289$ & $143-282$ & $212-358$ & $272-400$ & $169-257$ \\
mm & $212,63 \pm 24,30$ & $215,30 \pm 17,02$ & $298,28 \pm 30,50$ & $326,24 \pm 29,54$ & $208,41 \pm 17,62$ \\
\hline Berat (W) gr & $28-214$ & $103-304$ & $161-360$ & $188-590$ & $14-299$ \\
& $73,40 \pm 30,65$ & $189,33 \pm 42,40$ & $245,09 \pm 57,30$ & $312,06 \pm 94,37$ & $92,56 \pm 37,00$ \\
\hline Berat yang & $72,38 \pm 25,78$ & $187,37 \pm 32,05$ & $239 \pm 52,76$ & $308,14 \pm 75,91$ & $89,73 \pm 24,04$ \\
diprediksikan (Ws) & & & & & $25,24-276,12$ \\
\hline Berat Relatif (Wr) & $81,71-212,46$ & $45,8-228,42$ & $83,12-132,87$ & $53,17-129,35$ & $103,71 \pm 34,57$ \\
\hline Faktor kondisi & $101,28 \pm 19,13$ & $101,05 \pm 15,51$ & $100,95 \pm 14,48$ & $101,09 \pm 14,14$ & $1,88-360$ \\
Fulton (K) & $2,55-3,25$ & $2,79-4,06$ & $2,83-3,09$ & $2,61-3,08$ & $2,93 \pm 0,18$ \\
\hline $\begin{array}{l}\text { Indeks koefisien } \\
\left.\text { determinasi (R }{ }^{2}\right)\end{array}$ & $0,74 \pm 0,10$ & $3,37 \pm 0,10$ & $2,93 \pm 0,07$ & $2,94 \pm 0,08$ & 0,50 \\
\hline Indeks koefisien & 0,93 & 0,58 & 0,70 & 0,68 & 0,71 \\
korelasi (r) & & 0,76 & 0,83 & 0,82 & 3,12 \\
\hline Nilai b & 2,93 & 2,15 & 2,62 & 2,61 & \\
\hline
\end{tabular}

Sementara itu, analisis nilai $b$ pada kelima ikan yang disampling ada di Gambar 26. Pada ikan jelawat menunjukkan tipe pertumbuhan allometrik positif pola pertambahan berat tubuh lebih cepat dari pertambahan panjang tubuh, sehingga fisik ikan terlihat gemuk (Effendie, 2002). Pola pertumbuhan allometrik negatif pada ikan lais, biawan, baung, toman, menunjukan kondisi pertumbuhan berat ikan lebih lambat daripada pertambahan panjang. Dengan demikian, fisik ikan nampak pipih. Secara umum, nilai b dipengaruhi oleh kondisi fisiologis dan lingkungan. Faktor tersebut yaitu, $\mathrm{pH}$ dan suhu (Jennings dan Reynolds, 2001). Data parameter lingkungan yang terukur saat penelitian yaitu suhu $\pm 27,8{ }^{\circ} \mathrm{C}$; kedalaman sungai $70-80 \mathrm{~cm} ; \mathrm{pH}$ 5,5-6.5, mendukung pertumbuhan ikan yang ada di sungai Suwi (Nugroho et al., 2016). Di samping itu kondisi biologis yaitu perkembangan gonad dan ketersediaan makanan juga sangat mempengaruhi (Froese, 2006). Nilai b yang diperoleh antara ke lima jenis ikan tersebut berbeda-beda. Pengaruh terhadap ukuran panjang dan berat tubuh ikan sangat besar terhadap nilai $b$ yang diperoleh sehingga secara tidak langsung faktor-faktor yang berpengaruh terhadap ukuran tubuh ikan akan mempengaruhi pola variasi dari nilai $b$ (Effendie, 2002). 


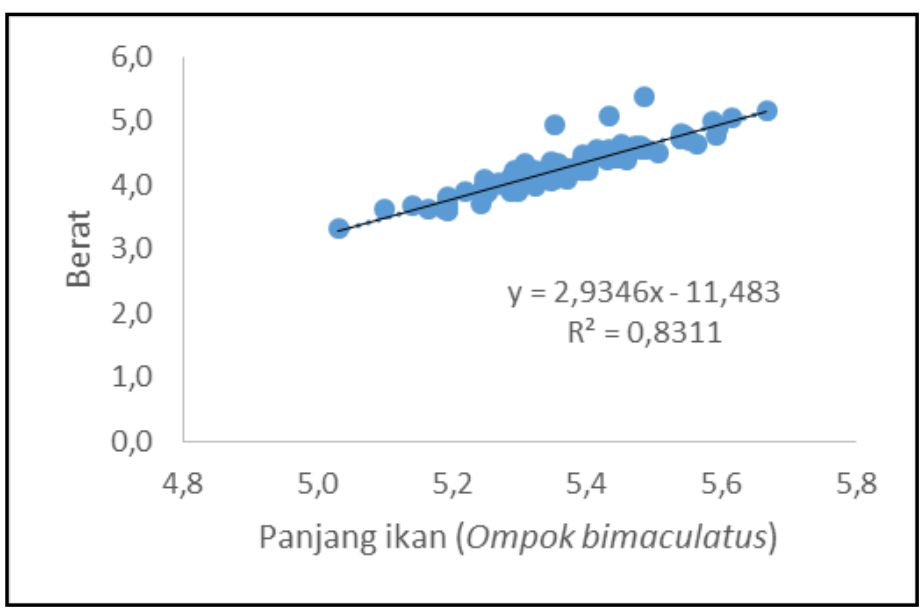

Gambar 2. Hubungan panjang berat (a) lais/lepok (Ompok bimaculatus) $\mathrm{n}=111$

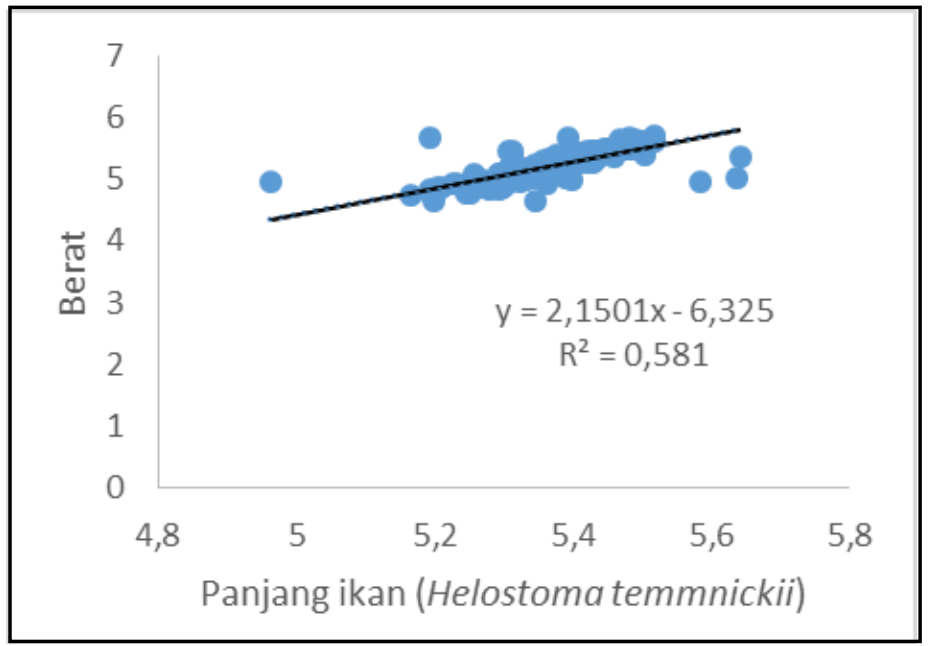

Gambar 3. Hubungan panjang berat (b) biawan (Helostoma temminckii) $\mathrm{n}=215$

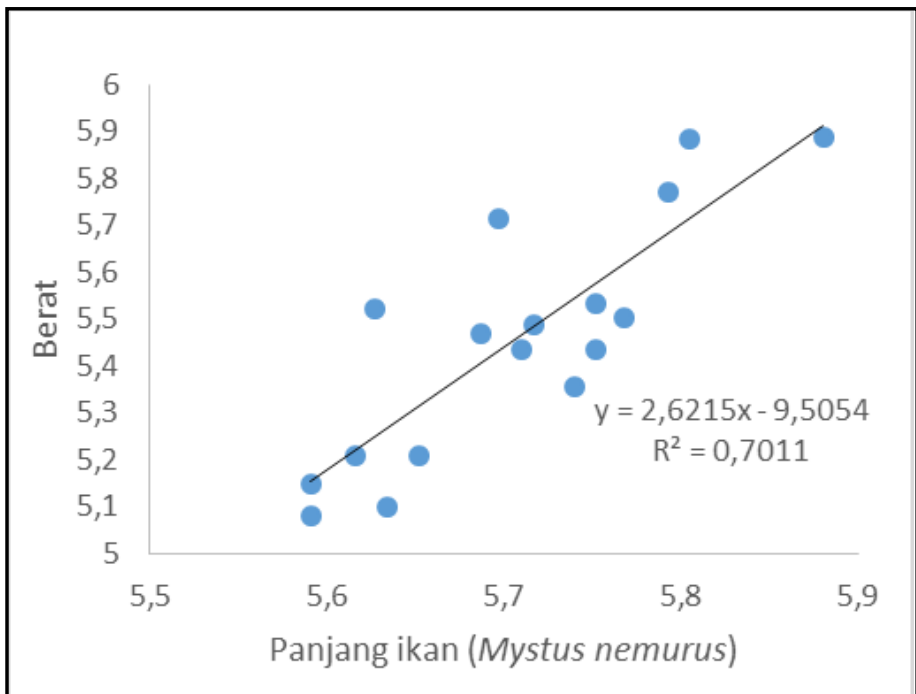

Gambar 4. Hubungan panjang berat (c) baung (Mystus nemurus) $\mathrm{n}=20$ 


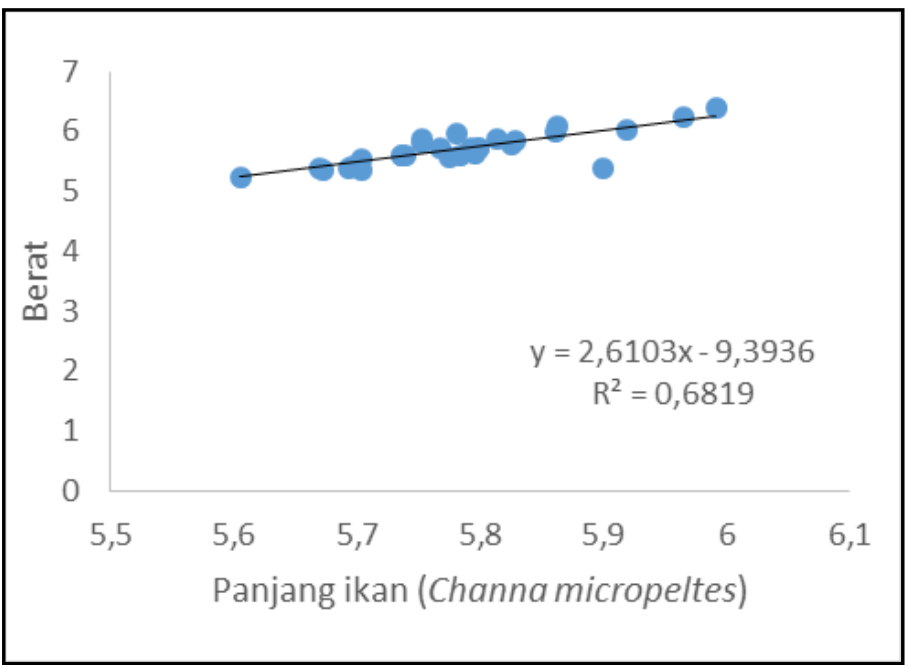

Gambar 5. Hubungan panjang berat, (d) toman (Channa micropeltes) $n=30$

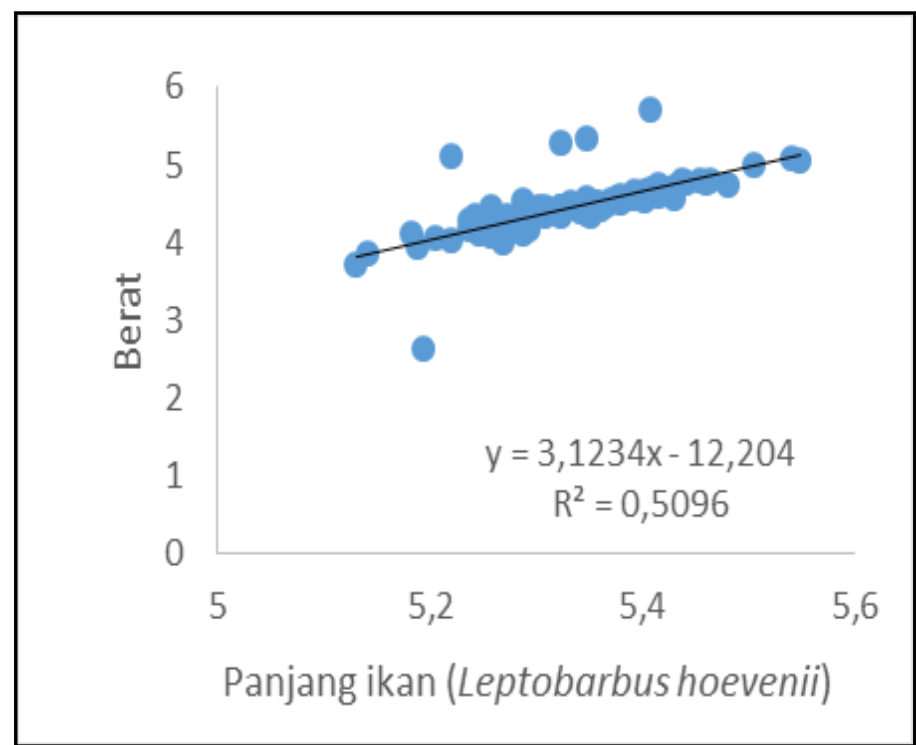

Gambar 6. Hubungan panjang berat, (e) ikan jelawat (Leptobarbus hoevenii) $\mathrm{n}=92$

\section{Simpulan}

Hubungan panjang-berat kelima jenis ikan yang disampling dari Sungai Suwi, Muara Ancalong bervariasi. Ditemukan pertumbuhan yang allometrik positif dan negatif. Faktor kondisi kelima jenis ikan menunjukan ketersediaan makanan yang cukup atau kepadatan predator rendah. Jenis predator yang ada adalah ikan-ikan karnivora yang berukuran besar. Penelitian selanjutnya disarankan untuk meneliti keberadaan predator yang mempengaruhi pertumbuhan ikan secara umum di sungai Suwi.

\section{Daftar Pustaka}

De-Robertis, A. K., and William. (2008). Weightlenght relationship in fisheries studies: the standard allometric model should applied with caution. Trans Am Fish Soc 137: 707719.

Effendie, M. I. (1997). Biologi Perikanan. Yayasan Pustaka Nusatama, Yayasan Pustaka Nusatama.

Effendie, M. I. (2002). Biologi Perikanan. Yayasan Pustaka Nusatama, Yogyakarta.

Ermayana, H. Arami, and F. Yasidi. (2018). Beberapa Parameter Reproduksi Ikan Kapas-Kapas (Gerres oyena) yang 
Tertangkap Pada Alat Tangkap Sero di Perairan Tondonggeu Kecamatan Abeli, Kota Kendari. Jurnal Manajemen Sumber Daya Perairan 4: 175-182.

Froese, R. (2006). Cube law, condition factor and weight length relationship: history, metaanalysis and recommendations. Journal of Applied Ichthyology 22: 241-253.

Jennings, S. M. J., and J. D. Reynolds. (2001). Marine fishery ecology Oxford. Blackwell Sciences.

Manik, N. (2009). Hubungan Panjang-Berat dan Faktor Kondisi Ikan Layang (Decapterus russelli) dari Perairan Sekitar Teluk Likupang Sulawesi Utara. Oseanologi dan Limnologi di Indonesia 35(1): 65-74

Muchlisin, Z. A. and S. H. Cheng. (2014). Hubungan Panjang Berat Dan Faktor Kondisi Tiga Spesies Cumi Hasil Tangkapan Nelayan Di Perairan Laut Aceh Bagian Utara. Jurnal Ilmu-ilmu Hayati dan Fisik 16: 72-77.

Muttaqin, Z., and I. D. D. Aliza. (2016). Kajian Hubungan Panjang Berat Dan Faktor Kondisi Ikan Nila (Oreochromis niloticus) Dan Ikan Belanak (Mugil cephalus) Yang Tertangkap Di Sungai Matang Guru, Kecamatan Madat, Kabupaten Aceh Timur. Jurnal Ilmiah Mahasiswa Kelautan dan Perikanan Unsyiah 1: 397-403.

Nugroho, R.A., Santoso, Y.G.G., Nur, F.M., Hariani, N. and Solikin, S., (2016). A preliminary study on the biodiversity of fish in the Suhui River, Muara Ancalong, East Kutai, Indonesia. AACL Bioflux, 9(2), pp.345-351.

Okgerman, H. (2005). Seasonal Variation of The Lenght Weight and Condition Factor of Rudd (Scardinius erythrophthalamus L) in Spanca Lake. International Journal of Zoological Research. 1(1) : 6-10.

Perikanan, K. K. (2018). Produktivitas Perikanan Indonesia. Jakarta.

Redjeki, S. (2003). Faktor Kondisi Dan Hubungan Panjang Berat Ikan Sebelah (Psettodes erumei) Di Perairan Jepara. Universitas Diponegoro, Semarang.

Rypel, A. L., and T. J. Richter. (2008). Emperical percentile standard weight equation for the Blacktail Redhorse. North American Journal of Fisheries Management 28: 1843-1846.

Trijoko, and S. Panoto. (2006). Keanekaragaman Jenis Ikan Di Sepanjang Airan Sungai Opak Daerah Istimewa Yogyakarta. Prosiding Seminar Nasional Ikan IV 06.

Umar, C., and Lismining. (2006). Analisis Hubungan Panjang - Berat Beberapa Jenis Ikan Asli Danau Sentani Papua. Seminar Nasional Ikan IV.

Walpole, R. E. (1995). Pengantar Statistika edisi Ke-3 alih Bahasa oleh Sumantri, B. PT Gramedia Pustaka Utama., Jakarta. 